\title{
RELATIONSHIP OF THE DURATION OF HEMODIALYSIS \\ IN CHRONIC RENAL FAILURE PATIENTS TO THE DEGREE OF CONGESTIVE HEART FAILURE BASED ON THE NEW YORK HEART ASSOCIATION IN NORTH LOMBOK HOSPITAL
}

\author{
I Kadek Dwi Iman Muliawan ${ }^{1}$, Kadek Dwi Pramana ${ }^{2}$ \\ General practitioner, Lombok Utara General Hospital, Lombok Utara, Indonesia \\ Internist, Lombok Utara General Hospital, Lombok Utara, Indonesia \\ Corresponding author: 1* I kadek Dwi Iman Muliawan. Lombok Utara General Hospital, Lombok Utara, \\ Indonesia. \\ Email : ikadek.dwi.iman@gmail.com
}

\begin{abstract}
Background :The hemodynamic relationship between the heart and the kidneys is closely related. Cardiorenal syndrome in general can be defined as a condition of pathophysiological disorders of the heart and kidneys, in which acute or chronic dysfunction of one organ results in acute or chronic dysfunction of other organs.. The cardiorenal syndrome proceeds like an interconnected loop where heart failure can exacerbate chronic kidney failure and vice versa.

Method : Research design analytic observational with cross sectional approach with the population is Chronic Kidney Failure (CKD) patients undergoing Hemodialysis (HD) program at North Lombok Hospital.

Aim : The purpose of this study was to see if there was a relationship between the duration of hemodialysis in CKD patients and the incidence of congestive heart failure (CHD).

Results : Statistical test results using Spearmen Test shows that from a total sample of 51 people, the correlation coefficient rof 0.446 and the value of Sig $(p)=0.001(p<0.05)$. Based on these results, it can be concluded statistically that there is a significant relationship between the length of HD and the degree of HF based on the New York Heart Association (NYHA).

Conclusion :There is a statistically significant relationship between the duration of HD and the degree of CHD based on the NYHA. The relationship is positive, which means that the longer the duration of HD, the higher the degree of NYHA in patients with CHD.
\end{abstract}

Keyword: GGK, GJK, HD, NYHA 


\section{Introduction}

Chronic renal failure (CKD) is a progressive kidney damage characterized by urine protein and decreased glomerular filtration rate (GFR) that lasts for more than 3 months. The Kidney Disease Outcomes Quality Initiative (K/DOQI) classifies CKD into 5 stages based on the decrease in GFR. Stage 1 with GFR $>90 \mathrm{ml} / \mathrm{min} / 1.73 \mathrm{~m} 2$, stage 2 with GFR $60-89 \mathrm{ml} / \mathrm{min} / 1.73 \mathrm{~m} 2$, stage 3 with GFR $30-59 \mathrm{ml} /$ minute $/ 1.73 \mathrm{~m} 2$, stage 4 with GFR 15-29 $\mathrm{ml} / \mathrm{min} / 1.73 \mathrm{~m} 2$ and stage 5 is also called terminal renal failure with GFR $<15 \mathrm{ml} / \mathrm{min} / 1.73 \mathrm{~m} 2$. (Marco Merta, 2012)

Heart failure is a condition where the heart is no longer able to pump blood to the tissues to meet the body's metabolic needs. The heart is responsible for supplying blood to body tissues and organs, including the kidneys, which function in maintaining fluid balance and salt homeostasis in the body. Therefore, disorders of the kidneys are often accompanied by heart failure and disorders of the heart are often accompanied by kidney failure. This interconnected relationship is known as "cardiorenal syndrome." The cardiorenal syndrome was first formally defined at the acute dialysis quality initiative (ADQI) consensus conference in 2009. This definition was created in an attempt to categorize the various associations between acute and chronic conditions in heart and kidney disease. 1 (Kingma et al., 2015)

Cardiorenal syndrome is defined aspathophysiological disorders of the heart and kidneys, where there is acute or chronic dysfunction in one organ resulting in other organ disorders. Other researchers define cardiorenal syndrome as a condition in which a combination of cardiac and renal dysfunction worsens the progressive failure of these organs, thereby increasing morbidity and mortality.( Marco Merta, 2012)

The association between impaired renal function and cardiovascular morbidity and mortality has even been seen in milder renal dysfunction. A large-scale epidemiological study involving more than 1 million people who were enrolled for an average of almost 3 years found a gradual decrease in the estimated glomerular filtration rate (GFR) below $60 \mathrm{ml} /$ minute associated with an increased risk of cardiovascular events, and duration hospital care (Go, AS, et al, 2004)

The underlying risk factors that are commonly found in kidney and heart dysfunction are age, hypertension, diabetes mellitus and atherosclerosis. These three classic factors are risk factors for cardiovascular disease and CKD, so it is understandable that there is a high interaction between these two diseases (Hasselblad, VN, 2008))

In CKD, fluid and sodium retention occur, resulting in an increase in atriovenous intravascular fluid overload. These changes will have an impact on changes in the structure of the arteries and heart. It all starts with an overload of intravascular fluid which will cause an increase in left ventricular end diastolic pressure which automatically interferes with stroke volume and cardiac output, thus affecting blood flow to all organs. Stimulation of the reninangiotensin-aldosterone system (RAAS) by the kidneys plays an important role in the occurrence of heart failure. Where the RAA stimulus causes left ventricular hypertrophy and arterial vasoconstriction. If this process lasts a long time, it will lead to heart failure in CKD patients (Frederique M, 2000). Hemodialysis is one of the therapies in End Stage Renal Disease (ERDS). 


\section{Methodology}

\subsection{Study Design and Research Population}

The research data was taken from 2019 to 2020. The type of research carried out was analytical observational with a cross sectional approach using anamnesis data through questionnaires and secondary data through medical records as a research reference. Place of research in North Lombok Hospital. The population of this study were all CKD patients who participated in the hemodialysis program at the North Lombok Hospital according to the exclusion and inclusion criteria.

The inclusion criteria in this patient were 1) The patient was willing to sign the informed consent; 2) Stage V CKD patients undergoing routine hemodialysis or who are not on hemodialysis for the first time. Exclusion criteria included 1) CKD patients who did not undergo hemodialysis; 2) Incomplete patient data in medical records; 3) patients with decreased patient consciousness or who are not willing to be respondents

The results of the study were obtained by taking data through medical records and interviews using a questionnaire that had been prepared based on the NYHA criteria to determineprogression of heart failure and quality of life of CKD patients undergoing $\mathrm{HD}$.

The data were analyzed statistically based on the variables assessed using a computerized system, namely univariate and bivariate analysis. Univariate analysis was conducted to see the frequency distribution of each independent variable and dependent variable. Bivariate analysis was conducted to analyze the relationship between the independent variable and the dependent variable. The relationship between the two variables was analyzed using the Sperarmen correlation test and was said to be related if the $\mathrm{p}$ value $<0.05$.

\section{Results}

This study was conducted on 51 CKD patients who underwent hemodialysis at the North Lombok Hospital in 20192020.

3.1. Univariat analysis

Table 1. Characteristics of Respondents

\begin{tabular}{llll}
\hline No & Characteristics & Frequency & $\%$ \\
\hline $1 \quad$ Gender & & \\
& a. Man & 30 & 58.8 \\
& b. Woman & 21 & 41.2 \\
& Age & & \\
& a. <45 years old & 13 & 25.5 \\
& b. 45-60 years old & 25 & 49.0 \\
& c. >60 -65 years old & 13 & 25.5 \\
& Hypertension & & \\
& a. History of HT & 47 & 92.2 \\
& b. No History of & 4 & 7.8 \\
4 & $\quad$ HT & & \\
& Diabetes & & \\
& a. DM history & 21 & 41.2 \\
& b. No history of & 30 & 58.8 \\
$\quad$ DM & & \\
\hline
\end{tabular}




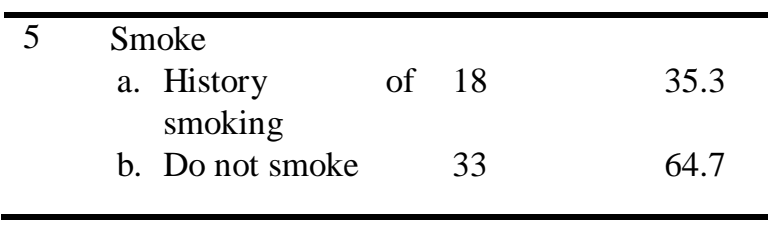

Based on Table 1 shows that most of the respondents are male, namely 30 people (58.8\%), and 21 people are female $(41.2 \%)$. Respondents with age <45 years were 13 people $(25.5 \%)$, age $45-60$ years were 25 people (49\%) and 60-65 years were 13 people $(25.5 \%)$.

Table 1 shows that 47 patients $(92.2 \%)$ had comorbid hypertension, 21 patients $(41.2 \%)$ had comorbid diabetes mellitus, 18 patients and $(35.3 \%)$ had a history of smoking.

Tabel 2. Distribution of Length of Undergoing Hemodialysis in CKD Patients

\begin{tabular}{lll}
\hline HD duration & Frequency & $\%$ \\
\hline$<6$ months & 9 & 17.6 \\
$>6$ months & 42 & 82.4 \\
Amount & 51 & $100 \%$ \\
\hline
\end{tabular}

Table 2. shows frequency distribution of duration of hemodialysis in CKD patients in North Lombok Hospital. In this study, it was found that most of the respondents underwent $\mathrm{HD}>6$ months, namely 42 people $(82.4 \%)$ and $<6$ months as many as 9 people $(17.6 \%)$.

Table 3. CHF distribution by NYHA

\begin{tabular}{ccc}
\hline NYHA & Frequency & $\%$ \\
\hline NYHA I & 2 & .9 \\
NYHA II & 10 & 19.6 \\
NYHA III & 27 & 52.9 \\
NYHA IV & 12 & 23.5 \\
Amount & 51 & $100 \%$ \\
\hline
\end{tabular}

Table 3, shows distribution of CKD based on the degree of NYHA in hemodialysis patients at the North Lombok Hospital.

Based on research conducted, respondents suffering from CHF based on the classification of heart failure by the New York Heart Association (NYHA), namely NYHA I as many as 2 people (0.9\%), NYHA II as many as 10 people (19.6\%), NYHA III as many as 27 people (52.9\%) and NYHA IV as many as 12 people $(23.5 \%)$. 


\subsection{Bivariate analysis}

3.2.1. The Relationship between the Length of Hemodialysis and the Degree of GJK according to NYHA

Statistical test results using Spearmen Test shows that from a total sample of 51 people obtained a correlation coefficient $r$ of 0.446 and the value of Sig $(p)=0.001(p<0.05)$. Based on these results, it can be concluded statistically that there is a significant relationship between the length of hemodialysis and the degree of CHF. The level of strength of the relationship between the duration of HD and the degree of HF based on the NYHA is 0.446 or sufficient. The type of relationship between the duration of $\mathrm{HD}$ and the degree of CKD is positive or unidirectional. Thus, it can be interpreted that the longer the duration of HD eating, the higher the degree of CHF based on the NYHA.

Table 4.Spearman-Rank Correlation Test Result

\begin{tabular}{ccc}
\hline Variable & $\begin{array}{c}\text { Correlation } \\
\text { coefficient value (r) }\end{array}$ & $\begin{array}{c}\text { Valuesig } \\
(\mathrm{p})\end{array}$ \\
\hline $\begin{array}{c}\text { Hemodialysis } \\
\text { duration- } \\
\text { NYHA class }\end{array}$ & .446 & 0.001 \\
\hline
\end{tabular}

\section{Discussion}

In this study, the number of male sex was 38 people (61.3\%), and 24 people were female (38.7\%). Based on gender, men have a 2-fold greater risk of CKD and CVD but after menopause the frequency is the same as women because men have less estrogen than women (Tifanny Chistine \& et al, 2018).

Based on the age category, the majority of the research respondents indicated the age of 45-60 years as many as 31 people $(50 \%)$.

At the age of $>50$ years, the kidneys will experience a significant decrease in function due to a decrease in the number of nephrons, which is $20 \%$ and will increase with increasing age. At an earlier age it is possible because of an unhealthy lifestyle (Ariyanto \& et al, 2018).

Of all study respondents who underwent hemodialysis showed that as many as 40 patients (64.5\%) had comorbid hypertension, 26 patients (41.9\%) had comorbid diabetes mellitus, 27 patients (43.5\%) had a history of smoking.

Hypertension is one of the main risk factors for cardiovascular disease and kidney damage. There are two mechanisms between hypertension and an increased risk of heart failure. First, hypertension can cause left ventricular hypertrophy which is associated with diastolic dysfunction and increases the risk of systolic heart failure. Both hypertension increase the risk of acute myocardial infarction which can lead to impaired left ventricular function and heart failure. in the kidney,Chronic increased pressure and strain on the small arteriolar and glomerular vessels of the kidney can cause endothelial dysfunction resulting in sclerosis which can block blood flow. Blockage 
of arterial and arteriolar flow will cause glomerular damage and tubular atrophy so that nephrons are damaged causing chronic kidney failure (Arief T \& et al, 2014).

Cigarettes contain nicotine. Nicotine can induce the adrenal glands to release catecholamine hormones (Intan Logani \& et al, 2017).

Diabetes mellitus is a risk factor for vascular disease. DM will increase mortality and morbidity 2 to 3 times compared to not having DM comorbid disease.Peter P Liu, 2008). As with hypertension, insulin resistance and hyperglycemia contribute to endothelial dysfunction and increased oxidative stress and can stimulate an overabundance of inflammatory cytokines in adipose tissue including interleukin (IL), IL-1, IL-6, Leptin, resistin MCP-1, PAI-1, fibrinogen (Maulina D. \& et al., 2019). So DM can increase the formation of atherosclerosis in the small arterioles of the kidney glomeruli and coronary blood vessels.

From the correlation test, it was found that there was a significant relationship between the duration of HD and the degree of HF based on the NYHA and this relationship had sufficient strength and the direction of the relationship was unidirectional. This means that the longer the duration of HD eating, the higher the degree of GJK based on the NYHA.

Dialysis is the main modality in End Stage Renal disease to prolong life expectancy. CKD and heart failure can increase mortality and morbidity and worsen the quality of life of CHF patients. Therefore, control of risk factors such as diabetes mellitus, hypertension and smoking also plays a very important role in addition to hemodialysis. Because in CKD patients there are two structural changes, namely the heart and arteries, where there is an increase in muscle mass of the left ventricle and arteries, thereby reducing elasticity and increasing peripheral resistance.

In addition, limiting fluid intake is very important. There are still many research subjects who pay less attention to fluid intake limits, fluid accumulation will add fluid overload and heart burden. The increase in fluid will automatically increase the fluid will be removed during hemodialysis with the ultrafiltration process (Lida F., 2015). During HD there is a risk of intradialytic hypotension, intradialytic hypotension reduces perfusion to tissues (cerebral, renal, myocardial and peripheral).

\section{Conclusion}

The relationship between the severity of chronic renal failure and the incidence of CHF is significant, meaning that the longer the duration of $\mathrm{HD}$, the higher the degree of CHF based on the NYHA.

\section{Acknowledgements}

First, I would like to thank Ida Sang Hyang Widhi Wasa for health and the opportunity to completes this research dan also my parent for support my study. Then thank dr Kadek Dwi Pramana Sp.PD for his guidance so far and the leaders at Nort Lombok Hospital. 


\section{References}

Arief T, Zulfachni W, Ibnu Fajar, 2014. Analysis of Factors Associated with Chronic Kidney Failure in Hmeodialysis Patients at Tugurajo Hospital Semarang. Faculty of Medicine Univ. Muhammadiah Seamarang.

Hasselblad, VN, Stebbins A, Et All, 2008, Cardiorenal Interactions: Insights From The Escape Trial. J Am Coll Cardiol ; 51(13):1268:74.

Hidayat F, 2013, Education of Cardiorenal Syndrome Patients in Efforts to Prevent and Increase Knowledge, Medical Education Study Program, Faculty of Medicine Sebelas Maret, Surakarta

Intan logani, Heedy T., Adityia Y,. Risk Factors for Chronic Kidney Failure at PROF Hospital. DR. RD Kandou Manado. Univ. Sam Ramtulangi, Manado.

Janis R., Ade Y,. 2015. Relationship of Mellitus with Chronic Kidney Failure. Faculty of Univ. Lampung: Lampung.

Jodi Sidarta L,2017, Cardiorenal Syndrome, Division of Kidneys and Hypertension, Section of the Senior High School of Internal Medicine

Kingma et al. Renocardiac Syndromes: Physiopathology And Treatment Strategies, Canadian Journal Of Kidney Health And Disease (2015) 2:41

Lida F,. 2015. The Relationship Between Comorbid Conditions And Mortality In Patients With Chronic Kidney Failure Undergoing Hemodialysis At Doctor Soedarso Hospital Pontianak. Univ. Tanjungpura: Pontianak.

Löfman I, Szummer K, Hagerman I, et al. 2016, Prevalence And Prognostic Impact Of Kidney Disease On Heart Failure Patients. Open Heart;3:E000324

Mulina J., Harvina S., Hanna M., Erwin S., jailani., Relationship between Blood Control and Morniing Blood Pressure Surge With Coronary Heart Disease Incidence in Type 2 Diabetes Mellitus Patients at Cut MEUTIA General Hospital. Malikussaleh University: Aceh.

Marco Metra, Et Al, 2012, The Role Oh The Kidney In Heart Failure, European Heart Journal 33, 2135-2143

Peter P Liu Md, 2008, Cardiorenal Syndrome In Heart Failure: A Cardiologist's Perspective, Can J Cardiol Vol 24

Schiffrin El, Lipman Ml, Mann Jfe, 2007, Chronic Kidney Disease: Effects On The Cardiovascular System. Circulation 116:85-97.

Systriana Esi, et al, 2018, Effect of Hemodialysis on the Kinetics of the Left Ventricular Segment in Patients with Chronic Kidney Disease Stage V, Nurseline Journal Vol. 3 No. May 1

Tifanny Christine \& Et Al,2018, Correlation between the severity of chronic kidney failure and the incidence of coronary heart disease, Diponegoro Medical Urnal Volume 7, Number 2, 